\title{
Using The Metaphysics Of Quality To Define Design Science
}

\author{
Christoph Bartneck \\ Department of Industrial Design \\ Eindhoven University of Technology \\ Den Dolech 2, 5600MB Eindhoven, NL \\ c.bartneck@tue.nl
}

\begin{abstract}
Design has evolved from a craft into an academic discipline, but it still falls short on defining its own science. I review previous approaches to Design Science and conclude that the subjectobject dualism is the one of the main obstacles. I then apply the Metaphysics of Quality to overcome the dualism and propose Quality as the phenomenon of Design Science. Next, I propose to utilize the analysis of interaction effects as a mean to investigate Quality. Last, I recommend steps we can take to mature this new Design Science and strategies how we can gain the acknowledgement of the other sciences.
\end{abstract}

\section{Categories and Subject Descriptors}

H.5.m Miscellaneous

\section{General Terms}

Design, Theory

\section{Keywords}

Metaphysics of Quality, Design, Theory, Science, Interaction Effect

\section{INTRODUCTION}

Design in all its flavors has a long history. Starting as a craft, it slowly developed into an academic field. By now, many universities have design faculties that offer programs at the bachelor, master and $\mathrm{PhD}$ level. But why stop there? Why not admit other crafts into the university, such as carpeting? It is surprisingly difficult to argue why design should be taught at a university and carpeting should not.

Both produce creative solutions to problems and implement them using technology. Both require theoretical knowledge, such as math and material sciences, and both have to satisfy the requirements of the users. Sometimes, I am even under the impression that carpenters know more math than my own design students. The academic design programs also have to compete with more practical design education programs that are being

Permission to make digital or hard copies of all or part of this work for personal or classroom use is granted without fee provided that copies are not made or distributed for profit or commercial advantage and that copies bear this notice and the full citation on the first page. To copy otherwise, or republish, to post on servers or to redistribute to lists, requires prior specific permission and/or a fee.

DESRIST'09, May 7-8, 2009, Malvern, PA, USA.

Copyright 2009 ACM 978-1-60558-408-9/09/05 ...\$5.00 offered by academies and applied schools. What then makes a university design faculty special? What do they offer that a carpeting school does not? Why do we need doctoral study in design [1] ?

The situation for designers in the area of information systems and technology (IST) is similar. The do create artifacts that support users and their organizations. There is no principal difference to the classical design or engineering faculties. IST may use maybe a little bit more math in their models, but the basic goal to satisfy the needs of the users remains the same. The arguments in this paper therefore apply to IST as well as to design.

I argue that along with gaining the recognition as an academic field there comes certain expectations. A university is not only an educational facility that prepares students for their careers, but also a place of science. Design at the university level is therefore expected to contribute to the development of scientific knowledge, in particular within the framework of a PhD program. This dedication to science is, in my view, what elevates a university design faculty. Science makes it special in comparison to more practical or artistic design education programs.

I use the term science instead of the term research with full intention. There is a great deal of ambiguity associated with the term "research". First, we need to distinguish between the verb research and the noun research. The noun is a synonym for science while the dictionary lists two meanings for the verb: to collect information and the process of conducting science. Designers mainly use the first definition [1] while scientists have no choice but to use the latter to describe their activities. They miss a verb form of science, such as "to science". It would therefore reduce the ambiguity of the term research considerably if the designers could use "to explore" to describe their activity to collect relevant information.

But also the noun research is not without different interpretations. It has been used, at least in my own department, to describe a weak form of science. Students conduct projects that explore new forms of interaction between users and technology. They do not tackle a concrete problem and neither do they apply the classical scientific method to produce knowledge. Instead, prototypes are being developed and casually evaluated. The resulting knowledge does therefore often score low on the criteria put forward for scientific knowledge, in particular on its generizablility [2]. Still, it would do injustice to these projects to state that no useful knowledge results from them at all. Everybody is aware that this is not classical science, but it is also clear that it is not classical problem solving either. In our department, these projects are therefore labeled "research". It is a compromise amongst the designers and scientists in our department. I am not certain if 
other academics made similar experiences, but from my discussions with colleagues, it appears as if not only my department uses this compromise. March and Smith [3] use the same compromise in their terminology and conclude their refelction about design science with that "There are virtually no generalizations or theories explaining about why and how (or even if) any of these artifacts work."

But why should we be satisfied with this compromise? Why do we not constitute a true Design Science? A science, which will not only gain the respect of the other sciences, but also a science that, will bring the field of design forward.

In this paper I will first review existing approaches of Design Science before I will detail the underlying problems of these approaches. Next, I will outline how the Metaphysics of Quality can resolve some of the underlying problems. Based on this, I will propose a draft for a new approach for Design Science and suggest concrete next steps.

\section{Short Review Of Design Science}

Maybe one of the most obvious definitions of Design Science could be design history. Design Science could focus on the results of the design (artifacts) and their creators (designers). A similar approach is taken in the fine arts. In most cases, obtaining a PhD in the area of art means art history. This would divide the design landscape into people that design and people that write about design. This is a perfectly valid view on Design Science, but it completely moves Design Science towards the humanities. It would become a form of critique and it is not clear how it could feed back into the design process.

A second definition of Design Science could be the usage of rational problem solving in the design process as it was proposed by Herbert Simon [4]. However, a method in itself cannot constitute a science. Let's take the example of the dissection method. Biologists may use dissection to analyze animals, but also butchers use it to cut steaks. The method is the same, but one results in scientific knowledge, while the other in a delicious meal. A method of investigation is a necessary condition, but not a sufficient condition.

A third definition could be the systematic organization of design relevant knowledge [5]. The organization of knowledge is an essential part of any science, but it will remain incomplete unless a method for acquiring the knowledge is included. Cross [6] therefore extended this view to "Explicitly organized, rational and wholly systematic approach to design: not just the utilization of scientific knowledge of artifacts, but design also in some sense as a scientific activity itself." His definition would merge the two previous views, but I believe that it is too early to come to a synthesis. For now, I will continue to treat them separately. Systematic knowledge is a necessary condition, but not a sufficient condition for a Design Science.

A fourth, and possibly the most popular definition of Design Science is the study of design methodologies. The topic of investigation is the question how do designers design. Design methodology, or to be more general, "human problem solving", has already been treated as a phenomena investigated by psychologists [7, 8]. Moreover, in the same way that biology is not a science of how biologists work, Design Science cannot be a science of how designers work.
The different views on what a Design Science could be highlight three aspects that most sciences have: an phenomenon under investigation, a method of investigation and systematic organization of the results of the investigation. To maintain the focus of this paper, I will have to leave the latter for another study. Let's first look at the problem of the missing phenomenon.

The sciences distinguish themselves not so much through their methods, but through the phenomena they investigate. Biology, for example, is the science of living organisms. What a Design Science is primarily missing is a clear definition of a phenomenon. The problem becomes clearer when we consider that design's prime focus lies in the intersection between artifacts and users (see Figure 1). Designers contribute to the creation of artifacts that interact with humans.

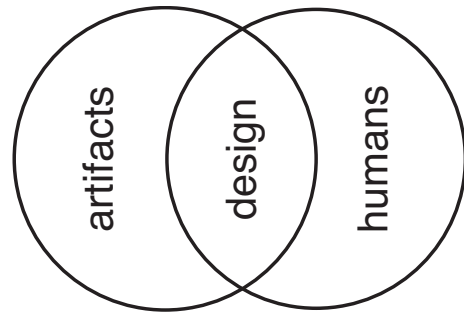

Figure 1: Phenomenon of Design

Everything there is to know about the artifact (left side Figure 1) is available from its creator. All its dimensions, material properties and functions are known. The artifacts are therefore unsuitable as phenomena for investigation because the creation of new materials and operational principles has already been claimed by engineering and physics. Both use rational design methodology that heavily relies on mathematics [4, 9, 10]. Pitt [11] even claimed that such a method would lead to knowledge that is "far more reliable, secure, and trustworthy than scientific knowledge". This means that the results are independent of the designer who applies them. This independence is a major step forward into the direction of generizability [2].

On the other side (right side Figure 1), understanding humans is the prime objective of medicine, and the social sciences. Design Science would have difficulties competing. Carroll even claimed that psychology alone is the science of design [12]. We have to conclude that both sides, artifacts and humans, have been claimed as phenomena by physics, engineering, medicine and the social sciences.

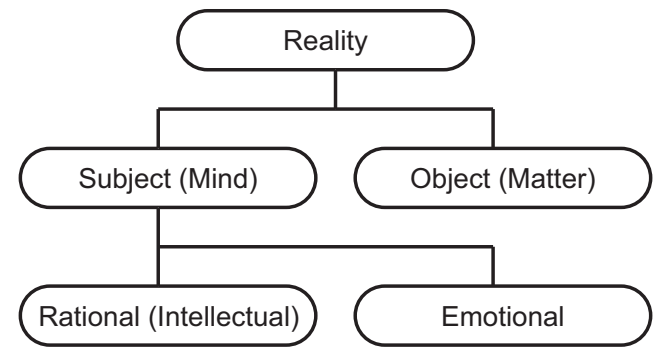

Figure 2: Cartesian dualism

Design is stuck in the middle without a clearly defined phenomenon to investigate. Currently, designers who want to work as scientists have to become either engineers or psychologists. Since they often lack training in these disciplines they have a natural disadvantage. I believe that this is one of the main obstacles in the creation of Design Science. 
So let's have a closer look at the source of the problem. The division of the phenomena depicted in Figure 1 follows the tradition of the subject-object split introduced by Descartes [13]. The separation of the body and the mind was a major step forward for the natural sciences because in this view of the world, the theory ('res cogitans') itself is clearly separated from and does not influence the described phenomena ['res extensa'; see Descartes [14], and more recently [15, chapter 7], and [16, chapter 17]]. In this Cartesian dualism, the world is separated into subjects and objects (see Figure 2). The mind is then further divided into rational and emotional thinking. This view of reality is familiar to us and easy to accept.

\section{METAPHYSICS OF QUALITY}

In the Cartesian duality, objective knowledge is superior to subjective knowledge and together they constitute an antagonistic relationship that constantly generates paired dichotomies: mind \& matter, science $\&$ art and feeling \& reason [17]. As useful as this division was for the foundation for modern science, it has also been severely criticized. Hevner et al. [18] pointed out that teachnolog (objects) and behaviour (subjects) are inseparable in an information system. Damasio [19] argued that the body is the genesis of thought and therefore no clear distinction between them can be made. But we need to go beyond unifying the brain and thought to overcome the true dualism between objects and subjects that inhibit the creation of a Design Science. I believe that Pirsig's Metaphysics of Quality (MOQ) holds the key to overcome this dualism [20,21] even though the status of his work within philosophy has been difficult. One of the major critiques is that Pirsig does not offer a systematic approach. While this is certainly true, a narrative approach has unique advantages and has already been successfully used in the dialogues of Plato. It makes ideas highly readable and understandable, which resulted in continued high sales of the book for over thirty years. It has even been argued that it is the best-sold philosophy book so far. Zen and the Art of Motorcycle Maintenance is even used as an introduction to the philosophy of science by certain universities. Still, many philosophers consider the book "pop-philosophy" whereas it does seem that the radical nature of the Metaphysics of Quality has not been sufficiently realized [22]. It does have the potential to reconcile art with reason, technology and science [23].

The MOQ reduces the duality between subjects and objects to a secondary role and places Quality (arête) alone at the top (see Figure 3) as "the parent, the source of all subjects and objects" [20]. Even though Quality itself cannot be defined, its existence can be proven. Pirsig provides a pragmatic proof by subtracting it from the description of our world and showing that a world without Quality would dysfunction [20].

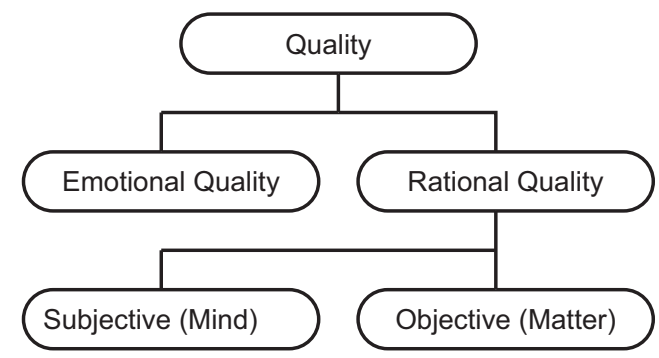

Figure 3: Ontology of Pirsig's Metaphysics of Quality
Pirsig eventually provides a description of Quality as being "the continuing stimulus which our environment puts upon us to create the world in which we live" [20]. To understand this statement one has to draw out the process of Quality (see Figure 4).

Our environment puts a Quality stimulus upon us, which we preintellectually sense before we intellectualize it and thereby divide it up in objects and subjects. The pre-intellectual sensibility to Quality is comparable to Kant's a priori pure cognition of time and space. It can even be argued that Quality might fulfill Kant's [24] requirements of necessity and universality and may hence be considered a third a priori pure cognition. Pirsig describes the sense of Quality like this:

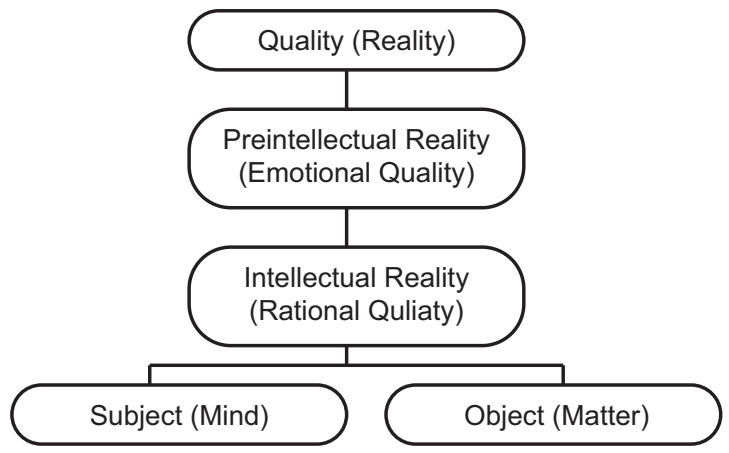

Figure 4: Process of Quality

This sense [for quality] is not just something you are born with, although you are born with it. It is also something you can develop. It is not just "intuition," not just unexplainable "skill" or "talent." It is the direct result of contact with basic reality, Quality, which dualistic reason has in the past tended to conceal. [20]

Notice that the good (Quality) is put on top in the MOQ (see Figure 3). This reverts Plato's original premise that the truth is above the good. To defeat the sophists (who are today's designers) Plato had to first unite the different ideas about the nature of such an immortal truth amongst the cosmologists. Heraclitus believed that the immortal principle would be change whereas Parmenides declared that all change is an illusion and that the immortal principle must be changeless. Socrates synthesized the positions by introducing a division between unchangeable forms and their variable appearances. The latter form a class of secondary reality, since they are not as constant as the forms. Plato clearly defines that what is most constant is what is most real. He then incorporated the sophists' arête into this dichotomy as being the highest form, only subordinate to truth and its dialectic method. He thereby encapsulated the good into the framework of reason and turned it from a relative entity into a constant form.

While one could use dialectic reason to discuss if the good is absolute or relative, it cannot be used to justify the superiority of truth above the good. Plato's premise that dialectic (or reason) "comes before everything else" is clearly erroneous. Dialectic presupposes knowledge of what is valuable and good, else why choose dialectic as a method and not the tossing of a die [25]. Scientists sometimes refuse to target their science towards utilitarian goals and demand that science should be conducted out of pure curiosity. Science should be aimed at the understanding of the world and free of values. But following Plato's error this is 
impossible. Preferring to know about the world is already a value judgment. Therefore science can never be free of values and values are above the truth.

Once arête was inside of the framework, Aristotle could then easily further depreciated it. But Aristotle introduced something of even greater importance that finalized the foundation of the western understanding of reality. He integrated Plato's unchangeable forms into the particular appearances. Reality is thereby constructed of objects that consist of variable matter and unchanging forms. To understand reality one has to look beneath the object's appearance to discover its internal form.

Our fundamental understanding of reality is based on Plato's and Aristotle's ideas. It is easy for us to accept a reality that consists of substance and which underlying forms can be understood by looking behind the objects and using reason to discover its ideal form. These days one would consider such an ideal form a law of physics. Science and in particular physics made astonishing progress since then and today it is very easy for us to accept an reality based on truth and very difficult to accept a reality of value.

A common critic on Pirsig's Metaphysics of Quality is the question how it could be possible that we disagree on Quality when Quality is supposed to be universal. How is it possible that we have difficulties agreeing on which is the more beautiful poem? Pirsig considers our previous experiences to influence our perception of Quality:

The names, the shapes and forms we give Quality depend only partly on the Quality. They also depend partly on the a priori images we have accumulated in our memory. We constantly seek to find, in the quality event, analogues to our previous experiences. If we didn't we'd be unable to act. We build up our language in terms of these analogues. ... The reason people see Quality differently is because people come to it with different sets of analogues. [20]

Pirsig speculated that if two people had identical a prior analogues they would see Quality identically every time. This would still not explain why listening to a new record over and over can change the experience from being exciting to being boring. In his second book Pirsig [21] evolves his original division of Quality into classical and romantic to a division of Quality into static and dynamic quality. The quality described in his first book (classical and romantic) is to be considered dynamic Quality. Pirsig [26] writes: "Dynamic Quality is a stream of quality events going on and on forever, always at the cutting edge of the present. But in the wake of this cutting edge are static patterns of value. These are memories, customs and patterns of nature." The main advantage of this division is that it prevents the perception that Quality consists of two types: classical and romantic. Furthermore, dynamic quality can more easily include mystical experiences, which according to Pirsig, are not well described by romantic Quality. The division between dynamic and static Quality then easily explain the change of experience in listening to a record numerous times. It changes from a dynamic quality to a static quality pattern. This new division also provides a different angle on the disagreement of what poem is more beautiful. While dynamic quality is the same for everyone, static quality patterns depend on the individual's prior experiences. When judging a poem we use both, dynamic and static Quality, which results in some uniformity among individual, but not complete uniformity. The dynamic Quality, and its division into classical and romantic
Quality, is of most importance here, since it is connection point between science and design:

What relates science to the arts [design] is that science explores the Conceptually Unknown [dynamic quality] in order to develop a theory that will cover measurable patterns emerging from the unknown. The arts [design] explore the Conceptually Unknown [dynamic quality] in other ways to create patterns such as music, literature, painting, that reveal the Dynamic Quality that produces them. - [26, square brackets added by the author]

Pirsig defined four patterns of static Quality that are order by the time they occurred in the evolution with each higher pattern more recent and more dynamic (see Figure 5).

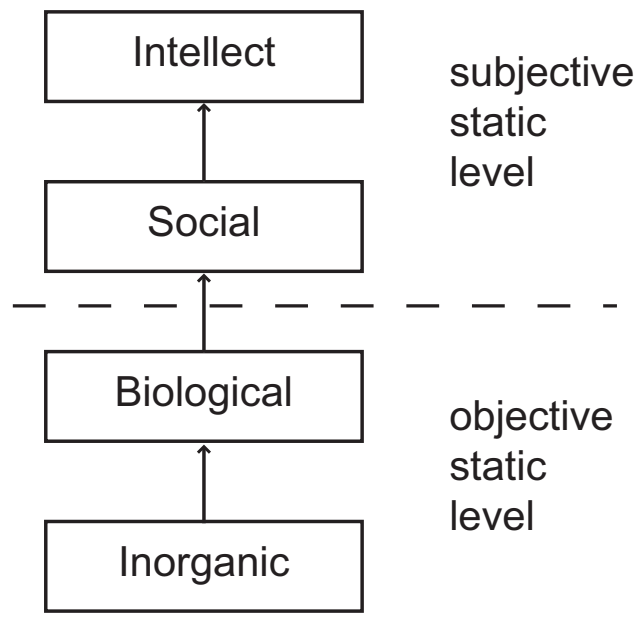

Figure 5: Static Quality patterns.

An extensive discussion of the static quality patterns is available elsewhere $[23,26]$ and I will only give a short introduction here. The intellect pattern at the top contains such as theology, science, philosophy, and mathematics. The placement of the intellect in this position makes it superior to social, biological and inorganic patterns but still inferior to Dynamic Quality. The social pattern includes such institutions as family, church and government. The social sciences are particularly interested in this pattern. The biological pattern includes senses of touch, sight, hearing, smell, taste and value. The inorganic pattern is composed of substance which Pirsig defines as "stable inorganic patterns of value". The inorganic and biological patterns can be referred to as objective static patterns while the social and intellectual pattern is considered subjective static patterns. It is important to notice that dynamic quality is constant and absolute, while static dynamic is subject to change. The laws of physic, for example, have evolved over time and the discovery of non-Euclidian geometries cast doubt on the foundation of the purest science of it all, mathematics. Poincare [27] concluded that scientific laws are not absolutely true, but merely a convention. He thereby introduced the human trait of convenience into science. This is certainly a step towards a humanistic science. But he was not the only one who looked at the influence of humans themselves on science. Both, Kuhn [28] and Feyerabend [29] showed that social forces have a strong influence on science. Moreover, the subjectivity is built into the scientific method itself. Scientists have to create and select a hypothesis to test from an indefinite number of possible hypotheses. This creation and selection does not follow a rational process but is based on the individual scientist's intuition: the sense of dynamic quality. The hypothesis that looks most 
interesting gets tested first. As Poincare pointed out, there must be a subliminal choice of what facts we observer.

When we now apply the MOQ to the problem of finding a phenomenon for Design Science we immediately notice that the MOQ resolves the subject-object split by introducing Quality as the source of all subjects and objects (see Figure 6). I propose that Design Science is the science of Quality.

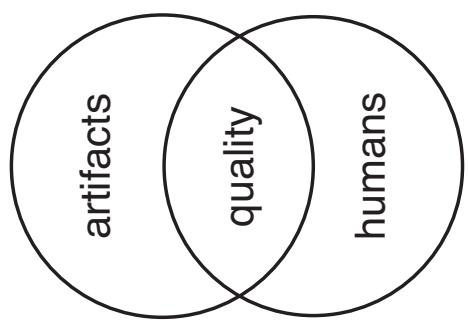

Figure 6: Quality as the phenomenon of Design Science

Like any other science, Design Science can use the method of analysis and synthesis to investigate Quality. Design methodology has many approaches available to synthesize quality. Roozenburg $\&$ Eekels [30] provide a good overview of existing methods, but what we are missing is an analysis method that does not prerequisite the subject-object split. The traditional scientific method is therefore only partially suitable, because it is based on exactly this split. The experimenter, for example, is assumed to have no influence on the experiment itself.

What we urgently need is a method that allows us to investigate Quality. I will now present a first draft of how we could utilize the established scientific method for this purpose. I have to admit that this draft is still in an early stage and that I do not yet have all the arguments in place to make it bulletproof. Hopefully it is at least good enough to serve as a starting point for a discussion.

The problem with trying to analyze Quality is that it is in the objects and subjects at the same time. It is always in the background but impossible to be measured in isolation. It might help to illustrate the problem with an analogy. Take the classical example of the correlation between firemen and damage. Whenever there are many firemen together, there is damage. One could think that the firemen cause the damage, but that is of course a wrong conclusion, since it is the fire that causes both of them to appear. In the same way that the fire is the reason for the appearance of firemen and damage, so is Quality for the emergence of subjects and objects. However, we do not yet have any direct means to measure Quality comparable to what we have for measuring fire.

So how can we investigate Quality if it cannot be defined and if there is no direct way of measuring it? Let's use the example of the firemen again and let's assume that we have no direct way of measuring fire. By systematically manipulating the factor "presence of firemen" we can approach insights into fire. We can have them convene at the fire department. We then have two factors to consider, the location and the presence of firemen. We will then observe that the amount of damage depends on the location and the presence of firemen (see Figure 7) at the same time.

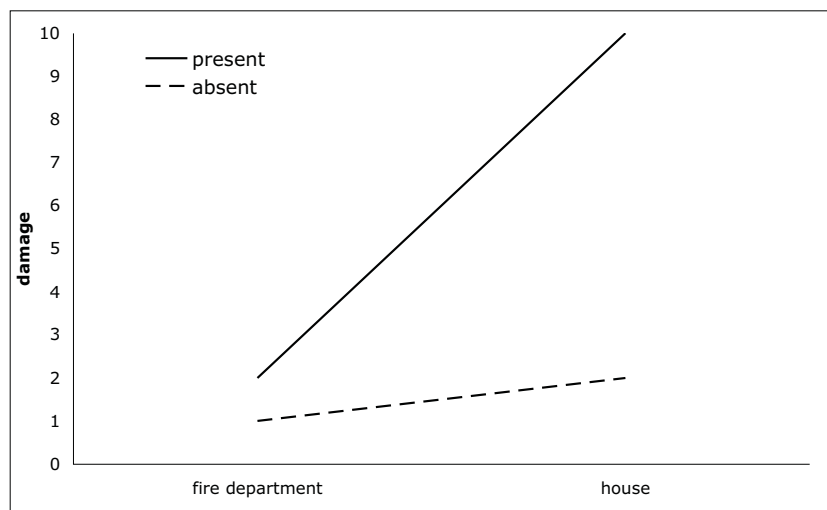

Figure 7: Mean damage across the firemen and location factors.

The factor presence of firemen and location interact with each other. In statistical terms, the interaction effect refers to one variable being different across levels of the other variable [31]. It is not in the focus of this paper to elaborate extensively on the mathematical model of the interaction effect, but let me in short denote that:

$$
\alpha \beta_{i j}=\mu_{i j}-\left(\mu+\alpha_{i}+\beta_{j}\right)
$$

where $\alpha \beta_{i j}$ denotes the deviation away from the cell-mean value that an independent effect model would predict.

$\mu_{i j}$ denotes mean in the $i$ th condition of one factor and the $j$ th condition of the other factor

$\mu$ denotes the grand mean of all conditions

$\alpha_{i}$ denotes the deviation from $\mu$ in the $i$ th condition of one factor

$\beta_{j}$ denotes the deviation from $\mu$ in the $j$ th condition of the other factor

While the mathematical definition of the interaction effect is clear, its interpretation remains difficult [32]. If we apply this principle to the investigation of Quality, we need to systematically manipulate subjects and objects at the same time and closely observe the interaction effect between the subject factor and the object factor. It follows that:

$$
\sigma o_{i j}=\mu_{i j}-\left(\mu+\sigma_{i}+o_{j}\right)
$$

where $\sigma o_{i j}$ denotes the deviation away from the cell-mean value that an independent effect model would predict. In other words, $\sigma o_{i j}$ measures how far each mean departs from additive effects.

$\mu_{i j}$ denotes mean in the $i$ th condition of the subject factor and the $j$ th condition of the object factor

$\mu$ denotes the grant mean of all conditions

$\sigma_{i}$ denotes the deviation from $\mu$ in the $i$ th condition of the subject factor $(\sigma=$ sigma $)$

$o_{j}$ denotes the deviation from $\mu$ in the $j$ th condition of the object factor $(\mathrm{o}=\mathrm{omicron})$

In the same way as we were able to exclude the firemen as being the sole source of the damage, we will also be able to gain new insights concerning Quality. This indirect method might be able to give us at least some knowledge about Quality.

Clearly, this approach is still just a sketch, but I have dwelled on it for a considerable amount of time and the discussion I had with 
my peers about it were encouraging. It is not a revolutionary approach, since it utilizes an existing method but I hope that this view on the interaction effect might at least provide a new perspective on the investigation of Quality.

\section{Conclusions}

The contact with this Conceptually Unknown, Quality, results in enthusiasm (gumption), which is of paramount importance for acting in the world. Maintaining enthusiasm and preventing to fall into gumption traps is Pirsig's concrete conclusion of his Metaphysics of Quality. He divides gumption traps into condition that arise from external circumstances (setbacks) and into conditions that arise from within oneself (hang-ups). Within the internal traps Pirsig further distinguishes between blocks of affective understanding (value traps), blocks of cognitive understanding (truth traps) and blocks of psychomotor behavior (muscle traps). There are possibly endless numbers of traps within these categories, but Pirsig describes only a few of them, including recommendations on how overcome them.

The analyses of the traps together with the possible solutions may hopefully lead to a return to individual integrity, self-reliance and old-fashioned gumption [20]. Pirsig concludes his Metaphysics of Quality by showing how it can be turned into everyday practice. Most of all we need to care and improve ourselves:

The real cycle you're working on is a cycle called yourself. The machine that appears to be "out there" and the person that appears to be "in here" are not two separate things. They grow toward Quality or fall away from Quality together. [20]

The effect of personal caring on the arts is familiar to us and Pirsig commented:

You want to know how to paint a perfect painting? It is easy. Make yourself perfect and then just paint naturally. [20]

The same holds true for designers, but in addition to an artistic skill they also need rationality to create good artifacts. The effect of caring and sensitivity to Quality in rational activities is less widely accepted even though Quality is the generator of all intellectual activity - both artistic and scientific [25]. Pirsig wrote:

The classic pattern of rationality can be tremendously improved, expanded and made far more effective through the formal recognition of Quality in its operation. [20]

The formal recognition of Quality will then have a direct influence on science:

I think that it will be found that a formal acknowledgement of the role of Quality in the scientific process does not destroy the empirical vision at all. It expands it, strengthens it and brings it far closer to actual scientific practice. ... By returning our attention to Quality it is hoped that we can get technological work out of the non-caring subject-object dualism and back into craftsmanlike self-involved reality again, which will reveal to us the facts we need when we are stuck. [20]

It will improve our selection of interesting hypotheses and facts. The knowledge creation of designers and scientists is very similar [10] and therefore Quality will also improve the more rational aspects of design. Both designers and scientist must improve themselves and the Quality of their work will improve naturally. They should also be aware of that both are approaching the same Quality. They only chose different emphases on subjective and objective Quality, which are dependent on each other. Quality is as much in a beautiful painting as it is in a running motorcycle and an elegant law of physics.

Besides improving ourselves and thereby the work we do, we also need to gain the respect of the other sciences, because otherwise we will always be at a disadvantage when it comes to the allocation of funding [1]. Clearly, this is a social process, but we are not the first to go through this. Pharmacology is also concerned with the creation of artifacts (drugs) that improve the current state of humans. It is possibly a good example on how a craft can mature into a science [33]. Given the high risks involved (e.g. the Contergan scandal), it is understandable that drugs need to pass serious tests before they are admitted. Other safety-critical design areas, such as airplane controls, also apply extensive testing. The strong empirical base of these research areas and the building of a systematic knowledge is one of the cornerstones towards acceptance as a science. It will take Design Science still some time before it can claim similar achievements, but every journey starts with a first step. As soon as the investigation methods for Quality have matured, I am certain that we can step up the speed.

\section{REFERENCES}

[1] Davis, M. Why Do We Need Doctoral Study in Design? International Journal of Design, 2, 3 2008), 71-79.

[2] Bartneck, C. What Is Good? - A Comparison Between The Quality Criteria Used In Design And Science. ACM, City, 2008. [3] March, S. T. and Smith, G. F. Design and natural science research on information technology. Decision Support Systems, 15, 4 1995), 251-266.

[4] Simon, H. A. The sciences of the artificial. MIT Press, Cambridge, Mass., 1996.

[5] Hubka, V. and Eder, W. E. Design science : introduction to needs, scope and organization of engineering design knowledge. Springer, Berlin ; New York, 1996.

[6] Cross, N. Science and design methodology: A review. Research in Engineering Design, 5, 2 1993), 63-69.

[7] Dorfman, J., Shames, V. A. and Kihlstrom, J. F. Intuition, incubation, and insight: implicit cognition in problem solving. Oxford University Press, City, 1996.

[8] Feist, G. The affective consequences of artistic and scientific problem solving. Cognition and emotion, 8(1994 1994), 489-502.

[9] Alexander, C. Notes on the synthesis of form. Harvard University Press, Cambridge, 1964.

[10] Vincenti, W. G. What engineers know and how they know it : analytical studies from aeronautical history. Johns Hopkins University Press, Baltimore, 1990.

[11] Pitt, J., C. What Engineers Know. Techne, 5, 3 2001), 17-30. [12] Carroll, J. M. HUMAN-COMPUTER INTERACTION: Psychology as a Science of Design. Annual Review of Psychology, 48, 1 1997), 61-83.

[13] Descartes, R. Meditations on first philosophy. Bobbs-Merrill Company, Indianapolis, 1960.

[14] Descartes, R. Principia Philosophiae. Danielem Elzevirium, Amsterdam, 1644.

[15] Dreyfus, H. L. What computers can't do : the limits of artificial intelligence. Harper \& Row, New York, 1979.

[16] Blackmore, S. J. The meme machine. Oxford University Press, Oxford [England] ; New York, 1999.

[17] Basalla, G. Man and Machine. Science, 1871975), 248-250. 
Bartneck, C. (2009). Using The Metaphysics Of Quality To Define Design Science

Proceedings of the 4th International Conference onDesign Science Research in Information Systems and Technology, Malvern, Pennsylvania, Article No. 6. | DOI: 10.1145/1555619.1555627

[18] Hevner, A. R., March, S. T., Park, J. and Ram, S. Design Science in Information Systems Research. MIS Quarterly, 28, 1 2004), \#4.

[19] Damasio, A. R. Descartes' error : emotion, reason, and the human brain. Quill, New York, 2000.

[20] Pirsig, R. M. Zen and the art of motorcycle maintenance: an inquiry into values. Morrow, New York, 1974.

[21] Pirsig, R. M. Lila : an inquiry into morals. Bantam Books, New York, 1991.

[22] Charlton, B., G. A Philosophical Novel: Zen and the Art of Motorcycle Maintenance by Rober M. Pirsig. Durham University Journal, 841992), 111-117.

[23] McWatt, A. An Introduction to Robert Pirsig's Metaphysics of Quality. Ph.D., University of Liverpool, Liverpool, 2003.

[24] Kant, I., Pluhar, W. S. and Kitcher, P. Critique of pure reason. Hackett Pub. Co., Indianapolis, Ind., 1996.

[25] Allis, U. Zen and the art of motorcycle maintenance. Critical Quarterly, 201978), 34-41.

[26] Pirsig, R. M. Subjects, Objects, Data \& Values. City, 1995.
[27] Poincare, H. and Maitland, F. Science and method. Thoemmes Press, Bristol, 1996.

[28] Kuhn, T. S. The structure of scientific revolutions. University of Chicago Press, Chicago, 1970.

[29] Feyerabend, P. K. Against method: outline of an anarchistic theory of knowledge. Humanities Press, London, 1975.

[30] Roozenburg, N. J. M. and Eekels, J. Product Design: Fundamentals and Methods. John Wiley \& Sons, Chichester, 1995.

[31] Smithson, M. Statistics with confidence. Sage Publications, London, 2000.

[32] González, A. B. d. and Cox, D. R. Interpretation of interaction: A review. Annals of Applied Statistics, 1, 2 2007), 371-385.

[33] Kremers, E., Urdang, G. and Sonnedecker, G. Kremers and Urdang's History of Pharmacy. American Institute of the History of Pharmac, Madison, 1986. 